\title{
Gene expression profiling analysis of the role of miR-22 in clear cell ovarian cancer
}

\author{
Y. B. ZHEN ${ }^{1}$, X. L. GUO ${ }^{2}$, B. XU ${ }^{3}$, H. W. ZHAO ${ }^{4}$, C. J. XU $U^{3, *}$ \\ ${ }^{1}$ Department of Neurosurgery, The First Affiliated Hospital of Harbin Medical University, Harbin, 150001, People's Republic of China; ${ }^{2}$ Department \\ of Gynecology, Maternal and child health care hospital, Zaozhuang, 277100, People's Republic of China; ${ }^{3}$ Obstetrics and Gynecology Hospital of \\ Fudan University, shanghai, 200090; ${ }^{4}$ Shanxi Province tumor hospital, Taiyuan, 030013
}

*Correspondence: congjian_xu987@163.com

\section{Received December 29, 2015 / Accepted May 31, 2016}

\begin{abstract}
This study aimed to investigate the role and potential mechanism of miR-22 in clear cell ovarian cancer (CCOC) progression. The gene expression profile of GSE16568, including 3 CCOC samples with miR-22 overexpression and 3 negative controls, was downloaded from the Gene Expression Omnibus database. Differentially expressed genes (DEGs) were screened using the limma package in R. Gene Ontology (GO) and pathway enrichment analysis of DEGs were performed by using The Database for Annotation, Visualization and Integrated Discovery (DAVID). Furthermore, protein-protein interaction (PPI) network of the DEGs was constructed using the Search Tool for the Retrieval of Interacting Genes (STRING) database. Besides, the miR-22 -mRNA interaction pairs were predicted to explore the critical genes involved in the cancer. Totally, 95 up-regulated DEGs and 51 down-regulated DEGs were identified. The DEGs were enriched in different GO terms and pathways. The up-regulated genes cyclin-dependent kinases (CDK6), MDM2 oncogene, E3 ubiquitin protein ligase (MDM2), and thrombospondin 1 (THBS1) were involved in the p53 signaling pathway. The up-regulated gene FBJ murine osteosarcoma viral oncogene homolog (FOS) was a hub protein in the PPI network of the DEGs. The down-regulated DEGs including lymphoid enhancer-binding factor 1 (LEF1) and v-myb avian myeloblastosis viral oncogene homolog (MYB) were mainly associated with immunity. Nine DEGs as target genes were identified to be recognized by miR-22. Our study suggested that several key genes such as CDK6, MDM2, LEF1, $M Y B$, and FOS that involved in different pathways including p53 signaling pathway were associated with CCOC progression. miR-22 may play an essential role in cell migration and invasion in CCOC through targeting responsive genes.
\end{abstract}

Key words: clear cell ovarian cancer, miR-22, differentially expressed genes, protein-protein interaction network, pathway analysis

Ovarian cancer (OC) is an extremely lethal gynecologic malignancy and is the fifth leading cause of cancer death among women $[1,2]$. Almost $90 \%$ to $95 \%$ of OC are epithelial ovarian cancer (EOC) which is thought to be derived from the ovarian surface epithelium or fallopian tube tissue or from ectopic endometrial [3]. EOC are classified into many histological subtypes, including serous, mucinous, endometrioid, and clear cell [4]. Clear cell ovarian cancer (CCOC) is the second most common histological subtype of $\mathrm{OC}$ after serous carcinoma [5]. The preferred treatment for CCOC is a complete resection of the tumor, but it is difficult to complete when the disease has been advanced [6]. Besides, the etiology of EOC remains poorly understood. Therefore, an improved understanding of the molecular circuitry in CCOC may significantly refine the management of the disease and may eventually lead to the development of more effective treatment modalities.
MicroRNAs (miRNAs) are small noncoding RNAs, usually 18-25 nucleotides in length, which inhibit translation and trigger mRNA degradation by binding to complementary sites in the $3^{\prime}$-untranslated region (UTR) of the target genes [7]. Commonly, alterations in the miRNA expression profiles detected between human cancer cells and their normal controls indicate that miRNAs are involved in the pathogenesis of cancer by acting like tumor suppressors or having oncogenic properties, or both in some cases [8]. Emerging evidence has established the role of miRNA in the pathogenesis of EOC [9, 10]. For example, miR-214 induces cell survival and cisplatin resistance primarily by targeting the phosphatase and tensin homolog (PTEN) in OC [9], and miR-199a can target CD44 to suppress the tumorigenicity and multidrug resistance of ovarian cancer initiating cells [11]. Bhattacharya et al. demonstrated that miR-15a and miR-16 controlled B lymphoma 
mouse Moloney leukemia virus insertion region (Bmi-1) expression and lead to significant decrease of cell proliferation and clonal growth in OC [12]. Recently, deregulation of miR-22 was reported to occur in various cancers and miR-22 was implicated in the regulation of various cellular processes, including motility and cell cycle [13]. For instance, Li et al. demonstrated that the tumor-suppressive role of miR-22 in p53-mutated colon cancers [14]. The work of Ling et al. reported that miR-22 suppressed lung cancer cell progression through the post-transcriptional regulation of Erb (estrogen receptor b) family member, ErbB3 [15]. Similarly, miR-22 was identified as a potential metastasis inhibitor in OC [13]. However, the role of miR-22 in ovarian cancer still remains largely unknown.

Using the same gene expression profiling, Nagaraja et $a l$. had demonstrated that miR-22 overexpression shifted the global gene expression pattern of CCOC toward a more normal state [16]. In the current study, we used microarray analysis to identify the differentially expressed genes (DEGs) in overexpressed miR-22 CCOC cell lines using hsa-miR-22 mimic transfection compared with negative controls. Comprehensive bioinformatics was used to analyze the significant pathways and functions and to construct the protein-protein interaction (PPI) network to find the critical DEGs. Furthermore, the target genes of miR-22 were predicted. The study was aimed to investigate the potential mechanism of human miR-22 in CCOC.

\section{Materials and methods}

Microarray data and data preprocessing. The microarray data of GSE16568, deposited by Nagaraja et al. [16], was downloaded from the Gene Expression Omnibus (GEO) database in National Center for Biotechnology Information (NCBI) (http://www.ncbi.nlm.nih.gov/geo/) based on the platform of GPL6947 Illumina HumanHT-12 V3.0 expression beadchip. A total of 6 specimens were applied, including 3 specimens of miR-22-overexpressing ES-2 ovarian cell lines which transfected with hsa-miR-22 mimics and another 3 specimens of negative control ES-2 ovarian cell lines which transfected with mimic negative control.

The gene expression profile data were preprocessed using the limma [17] package in Bioconductor and the chip definition file from Brainarray laboratory [18]. The gene expression matrix of specimens was received.

DEGs screening. T-test [17] in limma package was used to identify the DEGs in miR-22-overexpressing ES-2 ovarian cell line group compared with negative control group. False discovery rate (FDR) [19] was calculated for multiple testing correction using Benjamini and Hochberg method [20]. Threshold for the DEGs were set as FDR $<0.05$ and $\mid \log _{2}$ fold change (FC) $\mid \geq 2$.

Functional and pathway enrichment analysis of DEGs. In order to facilitate the functional annotation and pathway analysis, all the DEGs were analyzed using the Database for
Annotation Visualization and Integrated Discovery (DAVID) [21] to performed the Gene Ontology (GO) [22] and Kyoto Encyclopedia of Genes and Genomes (KEGG) [23] analysis. The $\mathrm{P}$ value $<0.05$ was chosen as the threshold.

Functional annotation of DEGs. Identification of tumorrelated genes and understanding their functions can be critical for studying the roles of genes involved in tumorigenesis. The tumor suppressor gene database (TSGene) (http://bioinfo. mc.vanderbilt.edu/TSGene/) is a comprehensive literaturebased database that provides detailed annotations for each TSG [24]. The tumor-associated gene (TAG) database (http:// www.binfo.ncku.edu.tw/TAG/) is designed to utilize information from well-characterized oncogenes and tumor suppressor genes to accelerate cancer research [25]. According to the data information of transcription factors (TFs), functional enrichment of the DEGs for transcription regulation was assessed. In addition, the selected DEGs were mapped into the TSGene and TAG database to extract the known oncogene and tumor suppressor genes.

PPI network construction. The PPI network is represented by an undirected graph with nodes indicating the genes and edges indicating the mapped interactions of the proteins encoded by the genes [26]. In this study, a PPI network was constructed by using data from the Retrieval of Interacting Genes (STRING) database which is a comprehensive database containing functional links between proteins that are experimentally derived as well as links predicted by comparative genomics and text mining [27]. The interaction pairs with the PPI combined score $>0.4$ were selected in this network, which corresponded to a medium-confidence network [28].

Prediction of miR-22 target genes. Computational algorithms for miRNA target prediction have been essential in order to identify the candidate targets. miR-22-mRNA interactions were predicted by using 5 miRNA target prediction algorithms, miRanda [29], MirTarget2 [30], PicTar [31], PITA [32], and TargetScan [33] for data obtaining. The selected DEGs which had overlap of at least 3 databases were considered as the potential target genes of miR-22.

\section{Results}

Screening of DEGs. A total of 149 transcripts were differentially expressed in miR-22-overexpressing CCOC groups compared with negative controls. Thereinto, 96 transcripts corresponding to 95 DEGs were up-regulated and 53 transcripts corresponding to 51 DEGs were down-regulated as shown in Table 1. Heat-map of the DEGs was shown in Figure 1. The

Table 1. The result of DEGs screening in overexpressed miR-22 CCOC

\begin{tabular}{lcc}
\hline Expression changes & Transcript Counts & Gene Counts \\
\hline Up-regulated & 96 & 95 \\
Down-regulated & 53 & 51 \\
Total & 149 & 146 \\
\hline
\end{tabular}




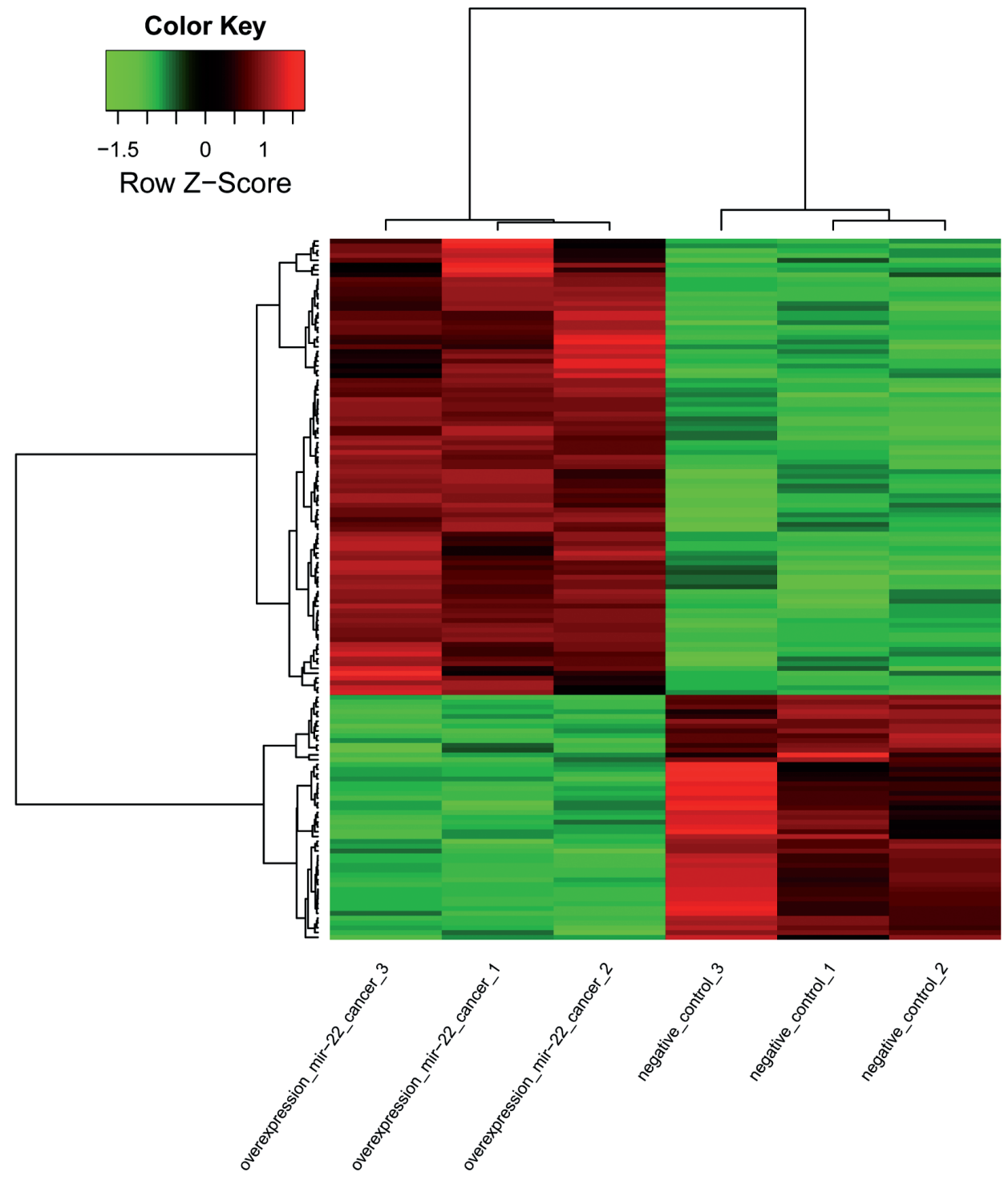

Figure 1. Heat map of the DEGs identified in overexpressed miR-22 CCOC compared with negative control. The red and green colors in the heat map indicate up-regulated and down-regulated DEGs respectively.

results showed that up-regulated genes were significantly more than the down-regulated genes.

Functional and pathway enrichment analysis of DEGs. Functional and pathway enrichment analysis indicated that the up-regulated DEGs and down-regulated DEGs in miR-22 -overexpressing CCOC groups were significantly enriched in different GO terms and KEGG pathways (Table 2 and Table 3 ). Seven KEGG pathways of up-regulated genes were mainly enriched, such as p53 signaling pathway, Cytokine-cytokine receptor interaction, and NOD-like receptor signaling pathway. Among these, cyclin-dependent kinases (CDK6), MDM2 oncogene, E3 ubiquitin protein ligase (MDM2), thrombospondin 1 (THBS1) were involved in p53 signaling pathway. Down-regulated DEGs were mainly enriched in
4 pathways, such as Glycerophospholipid metabolism and ErbB signaling pathway (Table 2). In addition, GO functional analysis showed that the up-regulated DEGs were mainly enriched in response to lipid and granulocyte chemotaxis, while the down-regulated DEGs such as lymphoid enhancerbinding factor 1 (LEF1) and v-myb avian myeloblastosis viral oncogene homolog $(M Y B)$ were mainly related to T-helper cell differentiation and alpha-beta $\mathrm{T}$ cell activation involved in immune response (Table 3 ).

Besides, the expression change of TFs, TSGs and oncogenes in miR-22-knockup CCOC cells were observed. The upregulated functional genes included 2 oncogenes and 4 TSGs, while the down-regulated functional genes included 4 TFs, 3 oncogenes and 1 TSG as shown in Table 4. 
Table 2. The enriched pathways of DEGs

\begin{tabular}{lcllll}
\hline $\begin{array}{l}\text { Expression } \\
\text { changes }\end{array}$ & KEGG-ID & \multicolumn{1}{c}{ Name } & Count & P-value & Genes \\
\hline Up & 5322 & Systemic lupus erythematosus & 9 & $3.55 E-08$ & HIST1H2AH,HIST1H2BC,HIST1H2BH,HIST1H3G,HI \\
& & & & & ST1H4B,HIST1H4E,HIST1H4H,HIST1H4K,HIST2H4A \\
Up & 5323 & Rheumatoid arthritis & 4 & 0.001568363 & CCL2,FOS,IL11,IL1B \\
Up & 5144 & Malaria & 3 & 0.002805802 & CCL2,IL1B,THBS1 \\
Up & 4115 & p53 signaling pathway & 3 & 0.006328311 & CDK6,MDM2,THBS1 \\
Up & 4060 & Cytokine-cytokine receptor interaction & 5 & 0.015185551 & CCL2,IL11,IL1B,IL24,PRLR \\
Up & 5142 & Chagas disease (American trypanosomiasis) & 3 & 0.020055339 & CCL2,FOS,IL1B \\
Up & 5219 & Bladder cancer & 2 & 0.022938192 & MDM2,THBS1 \\
Up & 4621 & NOD-like receptor signaling pathway & 2 & 0.041657608 & CCL2,IL1B \\
Down & 5412 & Arrhythmogenic right ventricular cardiomyopathy & 2 & 0.021055366 & ITGA10,LEF1 \\
Down & 564 & Glycerophospholipid metabolism & 2 & 0.024368124 & AGPAT9,LYPLA2 \\
Down & 4012 & ErbB signaling pathway & 2 & 0.028486545 & CAMK2D,CBL \\
Down & 4640 & Hematopoietic cell lineage & 2 & 0.029096523 & IL7,MME \\
Down & 4916 & Melanogenesis & 2 & 0.037496531 & CAMK2D,LEF1 \\
\hline
\end{tabular}

Table 3 The enriched GO terms of DEGs

\begin{tabular}{|c|c|c|c|c|c|}
\hline $\begin{array}{l}\text { Expression } \\
\text { changes }\end{array}$ & GO-ID & Name & Count & P-value & Genes \\
\hline Up & GO:0033993 & response to lipid & 12 & $2.23 \mathrm{E}-05$ & $\begin{array}{l}\text { ADM,CCL2,COL1A1,FOS,GSTM3,IL1B,IL24,MDK, } \\
\text { MDM2,PDE4B,PLSCR4,THBS1 }\end{array}$ \\
\hline Up & GO:0071621 & granulocyte chemotaxis & 5 & 2.87E-05 & CCL2,IL1B,PDE4B,SCG2,THBS1 \\
\hline Up & GO:0048545 & response to steroid hormone stimulus & 8 & $5.36 \mathrm{E}-05$ & $\begin{array}{l}\text { ADM,CCL2,COL1A1,FOS,GSTM3,MDK,MDM2,T } \\
\text { HBS1 }\end{array}$ \\
\hline Up & GO:0006950 & response to stress & 31 & $8.16 \mathrm{E}-05$ & $\begin{array}{l}\text { ADM,ALOX5AP,C10orf90,CA9,CCL2,CDK6,CO } \\
\text { L1A1,FOS,FXN,GBP2,GSTM3,HIST1H2BC,HSP } \\
\text { A6,IGFBP1,IL11,IL1B,IL1RL1,IL24,MDK,MDM } \\
\text { 2,NUAK2,PARD3,PLOD2,PLSCR4,PXDN,SCG } \\
\text { 2,SEL1L,SERPINA3,THBS1,TXK,VASN }\end{array}$ \\
\hline Up & GO:0014070 & response to organic cyclic compound & 11 & 0.000102053 & $\begin{array}{l}\text { ADM,CCL2,COL1A1,FOS,FXN,GSTM3,IL1B,MDK, } \\
\text { MDM2,PDE4B,THBS1 }\end{array}$ \\
\hline Down & GO:1902107 & positive regulation of leukocyte differentiation & 3 & 0.002701745 & IL7,LEF1,MYB \\
\hline Down & GO:0002294 & $\begin{array}{l}\text { CD4-positive, alpha-beta } \mathrm{T} \text { cell differentiation } \\
\text { involved in immune response }\end{array}$ & 2 & 0.003948496 & LEF1,MYB \\
\hline Down & GO:0042093 & T-helper cell differentiation & 2 & 0.003948496 & LEF1,MYB \\
\hline Down & GO:0002287 & $\begin{array}{l}\text { alpha-beta } \mathrm{T} \text { cell activation involved in immune } \\
\text { response }\end{array}$ & 2 & 0.004418705 & LEF1,MYB \\
\hline Down & GO:0002293 & $\begin{array}{l}\text { alpha-beta } \mathrm{T} \text { cell differentiation involved in im- } \\
\text { mune response }\end{array}$ & 2 & 0.004418705 & LEF1,MYB \\
\hline
\end{tabular}

Table 4. Functional annotation of DEGs in overexpressed miR-22 CCOC

\begin{tabular}{llll}
\hline & TF & Oncogene & TSG \\
\hline Up & NA & MDM2, FOS & THBS1, RARRES1, IL24, C10orf90 \\
Down & RFXANK, MYCBP, LEF1, HOXA4 & MYB, MME, CBL & FBXO32 \\
\hline
\end{tabular}

TF: transcription factor, TSG: tumor suppression genes, NA: not applicable.

PPI network construction. The PPI network included 41 nodes and 59 interactions (Figure 2). The results showed that the gene with highest node degree in the network was FBJ murine osteosarcoma viral oncogene homolog (FOS) (degree
$=14$ ), which was also identified to be up-regulated in miR-22knockup CCOC cells compared with negative controls.

Prediction of the miR-22 target genes. A total of 9 target genes of miR-22 were obtained, such as chromosome 17 open 


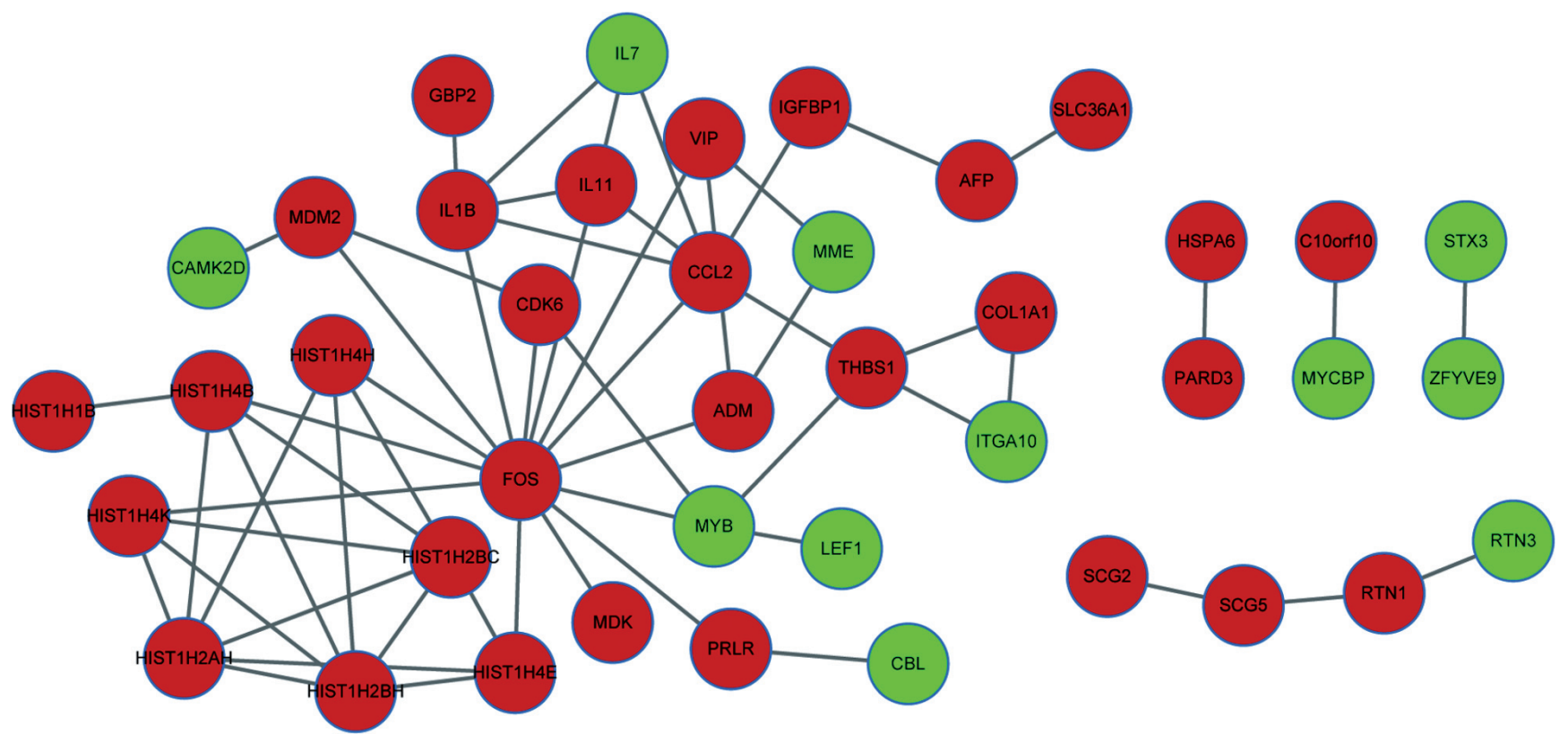

Figure 2 PPI network of DEGs. The red nodes indicate up-regulated genes and green nodes represent down-regulated genes.

reading frame 58 (C17orf58), enhancer of mRNA decapping 3 (EDC3), ring finger protein 38 (RNF38), testis-specific kinase 2 (TESK2), testis-specific kinase 2 (ZFYVE9), leucine rich repeat containing 1 (LRRC1), pre-mRNA processing factor 38A (PRPF38A), inositol polyphosphate-5-phosphatase (INPP5B), ANKHD1-EIF4EBP3 read through (ANKHD1-EIF4EBP3). All the 9 target genes in miR-22-knockup CCOC samples were down-regulated (Figure 3 ).

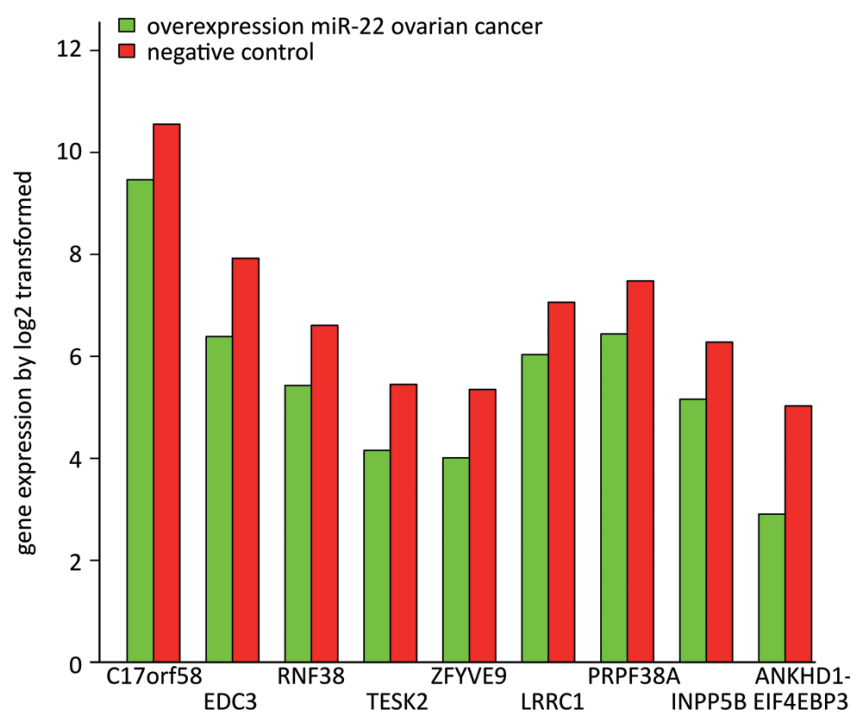

Figure 3. Expression level of the 9 target genes for miR-22. The red column indicates the overexpressed miR-22 CCOC group and the green column represents the negative control group.

\section{Discussion}

CCOC is an aggressive disease which is at large resistant to therapy due to the asymptomatic early stages and no screening program in place [34]. Though miR-22 as a tumor suppressor has been demonstrated to play a crucial role in human carcinogenesis [35], the role of miR-22 in OC progression still remains largely unknown. In this study, microarray analysis showed that 95 up-regulated DEGs and 51 down-regulated were identified in miR-22-knockup CCOC samples compared with negative controls. The up-regulated DEGs CDK6, MDM2, and THBS1 were involved in the p53 signaling pathway. FOS as an oncogene which was up-regulated was also a hub protein in the PPI network of the DEGs. The down-regulated DEGs including LEF1 and MYB were mainly associated with immunity. A total of 9 DEGs could be recognized by miR-22 in CCOC, such as EDC3, LRRC1, and RNF38.

CDK6 is a member of the CDK family which are heteromeric serine/threonine kinases that control progression and regulate mammalian cell division through the cell cycle in collaboration with their regulatory subunits, the cyclins [36]. D'Andrilli et al. reported that CDK6 as the G1 regulator played a crucial role in ovarian cancer tumoigenesis and development [37]. A study had shown that somatic p53 alteration leading to p53 accumulation which was in response to cellular stresses ranged from the induction of cell-cycle arrest for DNA repair to apoptosis for elimination of damaged cells after cell stress was an important event in hereditary ovarian cancer [38]. Besides, Mendrzyk found that CDK6 might link the TP53 (p53) tumor suppressor pathway to medulloblastoma pathogenesis [39]. Moreover, Tsuchiya et al. used functional 
genetic and comprehensive genomic screens and identified that miR-22 as a strong candidate for TSG determined the p53-dependent cellular fate [40]. On the other hand, MDM2 encodes a nuclear-localized E3 ubiquitin ligase which can promote tumor formation for the degradation of proteasome by targeting tumor suppressor proteins, such as p53 [41]. Chen et al. showed that MDM2 could bind the transcriptional activation domain of p53 and MDM2 onco-protein is a potent inhibitor of p53 [42]. In line with the previous studies, our study showed that the up-regulated DEGs, CDK6 and MDM2 were identified to be involved in p53 signaling pathway, suggesting that miR-22 may play a critical role in ovarian cancer through regulating the p53 signaling pathway. It is worthy of note, however, that the ES-2 used as described in the original study [16], a widely recognized CCOC cell line, was originally established from a poorly differentiated CCOC, which was derived from the surgical tumor specimen of a 47-year-old black woman [43]. Although TP53 mutations in CCOC are rare, a study demonstrated that ES2 was the only CCOC cell line harboring a missense mutation in TP53 (c. 722C>T, p.S241F) [44]. Therefore, this cell line should be used with caution as a valid model for studying CCOC [43]. Nevertheless, evidence shows high incidence of p53 gene mutation in human OC, which is associated with nuclear accumulation of $\mathrm{p} 53$ protein and tumor DNA aneuploidy [45]. How the TP53 missense mutation in the ES-2 acts is currently unclear. Besides, the results in this study were based on the computational analysis and findings of the previous studies. Thus, further experimental verifications are needed and we should repeat our work on mir-22 in other CCOC cell lines with wild type p53. Studies of the other CCOC cell lines are in progress in our research group.

LEF1 encodes a TF which binds to a functionally important site in the T-cell receptor- $\alpha$ enhancer [46]. LEF1 plays critical roles in normal thymocyte development and Yu et al. reported that LEF1 and T cell factor 1(TCF-1) had cooperative and opposing roles in $\mathrm{T}$ cell development as well as malignancy [47]. Curiel et al. demonstrated that specific recruitment of regulatory of $\mathrm{T}$ cells in ovarian cancer could foster immune privilege and predicted reduced survival [48]. MYB is a DNAbinding protein which contains three domains and the protein plays an essential role in the regulation of hematopoiesis [49]. Lahortiga et al. showed that a duplication of the MYB oncogene could be found in the $\mathrm{T}$ cell acute lymphoblastic leukemia [50]. Furthermore, Zhou et al. identified that cMYB and LEF1were required for optimal binding of each of them to the Bcl2, suggesting c-MYB and LEF1 interacted and cooperated in the activation of $\mathrm{Bcl} 2$ in leukemia cells [51]. As mentioned above, our findings showed that MYB and LEF1 which were both down-regulated had interactions from the PPI network. From the discussion, one may conclude that MYB may interact with LEF1 to affect T cell development in CCOC.

In addition, our findings revealed that FOS as an oncogene was the hub protein in the PPI network of DEGs. FOS encodes nuclear phosphoprotein which can dimerize with proteins of the jun proto-oncogene (JUN) family and has been implicated as regulators of cell proliferation, differentiation, and transformation [52]. Several studies had shown that FOS family might be involved in motility and adhesion of ovarian cancer cells $[53,54]$. Our data were in agreement with the findings, suggesting that FOS may play a crucial role in CCOC development by changing cells motility.

Furthermore, our studies identified 9 miR-22-mRNA interaction pairs. Among these, EDC3 is associated with a mRNA-decapping complex in the process of mRNA degradation which is indispensable to the post-transcriptional control of gene expression [55]. Schwartz demonstrated that gene expression in OC reflected both morphology and biological behavior [56]. Moreover, Nagaraja et al. reported EDC3 as responsive target of miR-22 was down-regulated in CCOC [16]. TESK2 is a serine/threonine protein kinase that can catalyze autophosphorylation and phosphorylation of exogenous substrates [57]. van Rheenen et al. reported that TESK2 could phosphorylate cofilin at serine 3 and altered cofilin expression had been found in OC [58]. Moreover, Toshima et al. revealed that cofilin and actin-depolymerizing factor (ADF) played an important role in the rapid turnover of actin filaments which were essential for cell movement and adhesion [59]. In addition, Li et al. had showed that miR-22 might be involved in inhibiting cell migration and invasion in OC [13]. Our data illustrated that miR-22 may play an essential role in CCOC metastasis via inhibiting the target genes expression.

In conclusion, our study identified several key genes (CDK6, $M D M 2, L E F 1$ and MYB, FOS) that participated in different pathways were involved in the mechanism of CCOC with overexpressed miR-22. CDK6 and MDM2 were involved in p53 signaling pathway. miR-22 may play a crucial role in ovarian cancer through regulating the p53 signaling pathway and further work on mir-22 in other CCOC cell lines are needed. MYB may interact with LEF1 to affect T cell development in CCOC. In addition, FOS may play a crucial role in CCOC development by changing cells motility. Furthermore, miR22 may play an essential role in cell migration and invasion in CCOC. However, sample size is less in our study, higher throughput data analysis and further studies are needed to determine the importance of DEGs and the potential role of miR-22 in our study. The miRNA targets identified in this study may serve to clarify the role of miR-22 in ovarian clear cell cancer as well as other cancer types. Ongoing studies with miR-22 may set the scene for the exciting potential of miR-22 therapeutics for prevention and treatment of CCOC.

\section{References}

[1] WANG K, LI Y, JIANG YZ, DAI CF, PATANKAR MS et al. An endogenous aryl hydrocarbon receptor ligand inhibits proliferation and migration of human ovarian cancer cells. Cancer Lett 2013; 340: 63-71. http://dx.doi.org/10.1016/j. canlet.2013.06.026 
[2] BROERSEN LH, VAN PELT GW, TOLLENAAR RA, MESKER WE. Clinical application of circulating tumor cells in breast cancer. Cell Oncol (Dordr) 2014; 37: 9-15. http:// dx.doi.org/10.1007/s13402-013-0160-6

[3] AUERSPERG N, WONG AS, CHOI KC, KANG SK, LEUNG PC. Ovarian surface epithelium: biology, endocrinology, and pathology. Endocr Rev 2001; 22: 255-288. http://dx.doi. org/10.1210/er.22.2.255

[4] SEIDMAN JD, HORKAYNE-SZAKALY I, HAIBA M, BOICE CR, KURMAN RJ et al. The histologic type and stage distribution of ovarian carcinomas of surface epithelial origin. Int J Gynecol Pathol 2004; 23: 41-44. http://dx.doi.org/10.1097/01. pgp.0000101080.35393.16

[5] FORD A, GREEN JA. Ovarian Clear Cell Carcinoma. p 83-90. In: N. Reed, J. Green, D. Gershenson, N. Siddiqui and R. Connor (Eds.), Rare and Uncommon Gynecological Cancers. A Clinical Guide, Springer Berlin Heidelberg, 2011, pp 233. 978-3-642-13491-3. http://dx.doi.org/10.1007/978-3-642$\underline{13492-0 \quad 7}$

[6] ITAMOCHI H, KIGAWA J, TERAKAWA N. Mechanisms of chemoresistance and poor prognosis in ovarian clear cell carcinoma. Cancer Sci 2008; 99: 653-658. http://dx.doi. org/10.1111/j.1349-7006.2008.00747.x

[7] MA R, JIANG T, KANG X. Circulating microRNAs in cancer: origin, function and application. J Exp Clin Cancer Res 2012; 31: 38. http://dx.doi.org/10.1186/1756-9966-31-38

[8] NANA-SINKAM SP, CROCE CM. MicroRNAs as therapeutic targets in cancer. Transl Res 2011; 157: 216-225. http://dx.doi. org/10.1016/j.trsl.2011.01.013

[9] YANG H, KONG W, HE L, ZHAO JJ, O`DONNELL JD et al. MicroRNA expression profiling in human ovarian cancer: miR-214 induces cell survival and cisplatin resistance by targeting PTEN. Cancer Res 2008; 68: 425-433. http://dx.doi. org/10.1158/0008-5472.CAN-07-2488

[10] HU X, MACDONALD DM, HUETTNER PC, FENG Z, EL NAQA IM et al. A miR-200 microRNA cluster as prognostic marker in advanced ovarian cancer. Gynecol Oncol 2009; 114: 457-464. http://dx.doi.org/10.1016/j. ygyno.2009.05.022

[11] CHENG W, LIU T, WAN X, GAO Y, WANG H. MicroRNA199a targets CD44 to suppress the tumorigenicity and multidrug resistance of ovarian cancer-initiating cells. FEBS J 2012; 279: 2047-2059. http://dx.doi.org/10.1111/j.1742-4658 $.2012 .08589 . \mathrm{x}$

[12] BHATTACHARYA R, NICOLOSO M, ARVIZO R, WANG E, CORTEZ A et al. MiR-15a and MiR-16 control Bmi-1 expression in ovarian cancer. Cancer Res 2009; 69: 9090-9095. http://dx.doi.org/10.1158/0008-5472.CAN-09-2552

[13] LI J, LIANG S, YU H, ZHANG J, MA D et al. An inhibitory effect of miR-22 on cell migration and invasion in ovarian cancer. Gynecol Oncol 2010; 119: 543-548. http://dx.doi. org/10.1016/j.ygyno.2010.08.034

[14] LI J, ZHANG Y, ZHAO J, KONG F, CHEN Y. Overexpression of miR-22 reverses paclitaxel-induced chemoresistance through activation of PTEN signaling in p53-mutated colon cancer cells. Mol Cell Biochem 2011;357:31-38. http://dx.doi. org/10.1007/s11010-011-0872-8
[15] LING B, WANG GX, LONG G, QIU JH, HU ZL. Tumor suppressor miR-22 suppresses lung cancer cell progression through post-transcriptional regulation of ErbB3. J Cancer Res Clin Oncol 2012; 138: 1355-1361. http://dx.doi. org/10.1007/s00432-012-1194-2

[16] NAGARAJA AK, CREIGHTON CJ, YU Z, ZHU H, GUNARATNE PH et al. A link between mir-100 and FRAP1/ mTOR in clear cell ovarian cancer. Mol Endocrinol 2010; 24: 447-463. http://dx.doi.org/10.1210/me.2009-0295

[17] SMYTH G. limma: Linear Models for Microarray Data. $p$ 397-420. In: R. Gentleman, V. Carey, W. Huber, R. Irizarry and S. Dudoit (Eds.), Bioinformatics and Computational Biology Solutions Using R and Bioconductor, Springer-Verlag New York, 2005, pp 474. 978-0-387-25146-2.

[18] SANDBERG R, LARSSON O. Improved precision and accuracy for microarrays using updated probe set definitions. BMC Bioinformatics 2007; 8: 48. http://dx.doi.org/10.1186/14712105-8-48

[19] REINER-BENAIM A. FDR control by the BH procedure for two-sided correlated tests with implications to gene expression data analysis. Biom J 2007; 49: 107-126. http://dx.doi. org/10.1002/bimj.200510313

[20] Benjamini Y, Hochberg Y. Controlling the false discovery rate: a practical and powerful approach to multiple testing. J Royal Stat Soc 1995; 289-300.

[21] HUANG DA W, SHERMAN BT, LEMPICKI RA. Systematic and integrative analysis of large gene lists using DAVID bioinformatics resources. Nat Protoc 2009; 4: 44-57. http://dx.doi. org/10.1038/nprot.2008.211

[22] ASHBURNER M, BALL CA, BLAKE JA, BOTSTEIN D, BUTLER $\mathrm{H}$ et al. Gene Ontology: tool for the unification of biology. The Gene Ontology Consortium. Nat Genet 2000; 25: 25-29. http://dx.doi.org/10.1038/75556

[23] KANEHISA M, GOTO S. KEGG: kyoto encyclopedia of genes and genomes. Nucleic Acids Res 2000; 28: 27-30. http://dx.doi. org/10.1093/nar/28.1.27

[24] ZHAO M, SUN J, ZHAO Z. TSGene: a web resource for tumor suppressor genes. Nucleic Acids Res 2013; 41: D970-D976. http://dx.doi.org/10.1093/nar/gks937

[25] CHEN JS, HUNG WS, CHAN HH, TSAI SJ, SUN HS. In silico identification of oncogenic potential of fyn-related kinase in hepatocellular carcinoma. Bioinformatics 2013; 29: 420-427. http://dx.doi.org/10.1093/bioinformatics/ bts715

[26] KOHLER S, BAUER S, HORN D, ROBINSON PN. Walking the interactome for prioritization of candidate disease genes. Am J Hum Genet 2008; 82: 949-958. http://dx.doi. org/10.1016/j.ajhg.2008.02.013

[27] FRANCESCHINI A, SZKLARCZYK D, FRANKILD S, KUHN M, SIMONOVIC M et al. STRING v9. 1: proteinprotein interaction networks, with increased coverage and integration. Nucleic Acids Res 2013; 41: D808-D815. http:// dx.doi.org/10.1093/nar/gks1094

[28] VON MERING C, HUYNEN M, JAEGGI D, SCHMIDT S, BORK P et al. STRING: a database of predicted functional associations between proteins. Nucleic Acids Res 2003; 31: 258-261. http://dx.doi.org/10.1093/nar/gkg034 
[29] BETEL D, WILSON M, GABOW A, MARKS DS, SANDER C. The microRNA. org resource: targets and expression. Nucleic Acids Res 2008; 36: D149-D153. http://dx.doi. org/10.1093/nar/gkm995

[30] WANG X, EL NAQA IM. Prediction of both conserved and nonconserved microRNA targets in animals. Bioinformatics 2008; 24: 325-332. http://dx.doi.org/10.1093/bioinformatics/ btm595

[31] CHEN K, RAJEWSKY N. Natural selection on human microRNA binding sites inferred from SNP data. Nat Genet 2006; 38: 1452-1456. http://dx.doi.org/10.1038/ng1910

[32] KERTESZ M, IOVINO N, UNNERSTALL U, GAUL U, SEGAL E. The role of site accessibility in microRNA target recognition. Nat Genet 2007; 39: 1278-1284. http://dx.doi. org/10.1038/ng2135

[33] LEWIS BP, BURGE CB, BARTEL DP. Conserved seed pairing, often flanked by adenosines, indicates that thousands of human genes are microRNA targets. Cell 2005; 120: 15-20. http://dx.doi.org/10.1016/j.cell.2004.12.035

[34] TSUCHIYA A, SAKAMOTO M, YASUDA J, CHUMA M, OHTA T et al. Expression profiling in ovarian clear cell carcinoma: identification of hepatocyte nuclear factor- $1 \beta$ as a molecular marker and a possible molecular target for therapy of ovarian clear cell carcinoma. Am J Pathol 2003; 163: 2503-2512. http://dx.doi.org/10.1016/S0002-9440(10)63605-X

[35] ZHANG G, XIA S, TIAN H, LIU Z, ZHOU T. Clinical significance of miR-22 expression in patients with colorectal cancer. Med Oncol 2012; 29: 3108-3112. http://dx.doi.org/10.1007/ s12032-012-0233-9

[36] GROSSEL MJ, HINDS PW. From cell cycle to differentiation: an expanding role for cdk6. Cell Cycle 2005; 5: 266-270.

[37] D'ANDRILLI G, KUMAR C, SCAMBIA G, GIORDANO A. Cell cycle genes in ovarian cancer: steps toward earlier diagnosis and novel therapies. Clin Cancer Res 2004; 10: 8132-8141. http://dx.doi.org/10.1158/1078-0432.CCR-04-0886

[38] ZWEEMER RP, SHAW PA, VERHEIJEN RM, RYAN A, BERCHUCK A et al. Accumulation of p53 protein is frequent in ovarian cancers associated with BRCA1 and BRCA2 germline mutations. J Clin Pathol 1999; 52: 372-375. http://dx.doi. org/10.1136/jcp.52.5.372

[39] MENDRZYK F, RADLWIMMER B, JOOS S, KOKOCINSKI F, BENNER A et al. Genomic and protein expression profiling identifies CDK6 as novel independent prognostic marker in medulloblastoma. J Clin Oncol 2005; 23: 8853-8862. http:// dx.doi.org/10.1200/JCO.2005.02.8589

[40] TSUCHIYA N, IZUMIYA M, OGATA-KAWATA H, OKAMOTO K, FUJIWARA Y et al. Tumor suppressor miR-22 determines p53-dependent cellular fate through post-transcriptional regulation of $\mathrm{p} 21$. Cancer Res 2011; 71: 4628-4639. http://dx.doi.org/10.1158/0008-5472.CAN-10$\underline{2475}$

[41] SDEK P, YING H, CHANG DL, QIU W, ZHENG H et al. MDM2 promotes proteasome-dependent ubiquitin-independent degradation of retinoblastoma protein. Mol Cell 2005; 20: 699-708. http://dx.doi.org/10.1016/j.molcel.2005.10.017
[42] Chen J, Lin J, LEVINE AJ. Regulation of transcription functions of the p53 tumor suppressor by the mdm-2 oncogene. Mol Med 1995; 1: 142.

[43] KWOK ALM, OSCAR GEE-WAN W, WONG ESY, OBE KALAI T, KA-KUI C et al. Caution over use of ES2 as a model of ovarian clear cell carcinoma. J Clin Pathol 2014; 67: 921-922. http://dx.doi.org/10.1136/jclinpath-2014-202430

[44] TAN DSP, LAMBROS MBK, SYDONIA R, RACHAEL N, RADOST $\mathrm{V}$ et al. PPM1D is a potential therapeutic target in ovarian clear cell carcinomas. Clin Cancer Res 2009; 15: 2269-2280. http://dx.doi.org/10.1158/1078-0432.CCR-08$\underline{2403}$

[45] KIHANA T, TSUDA H, TESHIMA S, OKADA S, MATSUURA S et al. High Incidence of p53 Gene Mutation in Human Ovarian Cancer and Its Association with Nuclear Accumulation of p53 Protein and Tumor DNA Aneuploidy. Jpn J Cancer Res 1992; 83: 978-984. http://dx.doi.org/10.1111/ j.1349-7006.1992.tb02010.x

[46] RIESE J, YU X, MUNNERLYN A, ERESH S, HSU S-C et al. LEF-1, a Nuclear Factor Coordinating Signaling Inputs from wingless and decapentaplegic. Cell 1997; 88: 777-787. http:// dx.doi.org/10.1016/S0092-8674(00)81924-8

[47] YU S, ZHOU X, STEINKE FC, LIU C, CHEN S-C et al. The TCF-1 and LEF-1 transcription factors have cooperative and opposing roles in $\mathrm{T}$ cell development and malignancy. Immunity 2012; 37: 813-826. http://dx.doi.org/10.1016/j. immuni.2012.08.009

[48] CURIEL TJ, COUKOS G, ZOU L, ALVAREZ X, CHENG $\mathrm{P}$ et al. Specific recruitment of regulatory $\mathrm{T}$ cells in ovarian carcinoma fosters immune privilege and predicts reduced survival. Nat Med 2004; 10: 942-949. http://dx.doi.org/10.1038/ $\underline{\mathrm{nm} 1093}$

[49] OH I-H, REDDY EP. The myb gene family in cell growth, differentiation and apoptosis. Oncogene 1999; 18: 3017-3033. http://dx.doi.org/10.1038/sj.onc.1202839

[50] LAHORTIGA I, DE KEERSMAECKER K, VAN VLIERBERGHE P, GRAUX C, CAUWELIER B et al. Duplication of the MYB oncogene in T cell acute lymphoblastic leukemia. Nat Genet 2007; 39: 593-595. http://dx.doi.org/10.1038/ng2025

[51] ZHOU F, ZHANG L, VAN LAAR T, VAN DAM H, TEN DIJKE P. GSK3 $\beta$ inactivation induces apoptosis of leukemia cells by repressing the function of c-Myb. Mol Biol Cell 2011; 22: 3533-3540. http://dx.doi.org/10.1091/mbc.E11-06-0483

[52] ANGEL P, KARIN M. The role of Jun, Fos and the AP-1 complex in cell-proliferation and transformation. Biochim Biophys Acta 1991; 1072: 129-157. http://dx.doi.org/10.1016/0304419x(91)90011-9

[53] TCHERNITSA OI, SERS C, ZUBER J, HINZMANN B, GRIPS $M$ et al. Transcriptional basis of KRAS oncogenemediated cellular transformation in ovarian epithelial cells. Oncogene 2004; 23: 4536-4555. http://dx.doi.org/10.1038/ sj.onc. 1207585

[54] MILDE-LANGOSCH K. The Fos family of transcription factors and their role in tumourigenesis. Eur J Cancer 2005; 41: 2449-2461. http://dx.doi.org/10.1016/j.ejca.2005.08.008

[55] EULALIO A, REHWINKEL J, STRICKER M, HUNTZINGER E, YANG S-F et al. Target-specific requirements for 
enhancers of decapping in miRNA-mediated gene silencing. Genes Dev 2007; 21: 2558-2570. http://dx.doi.org/10.1101/ gad.443107

[56] SCHWARTZ DR, KARDIA SL, SHEDDEN KA, KUICK R, MICHAILIDIS G et al. Gene expression in ovarian cancer reflects both morphology and biological behavior, distinguishing clear cell from other poor-prognosis ovarian carcinomas. Cancer Res 2002; 62: 4722-4729.

[57] TOSHIMA J, TOSHIMA JY, TAKEUCHI K, MORI R, MIZUNO K. Cofilin phosphorylation and actin reorganization activities of testicular protein kinase 2 and its predominant expression in testicular Sertoli cells. J Biol Chem 2001; 276: 31449-31458. http://dx.doi.org/10.1074/jbc.M102988200

[58] VAN RHEENEN J, CONDEELIS J, GLOGAUER M. A common cofilin activity cycle in invasive tumor cells and inflammatory cells. J Cell Sci 2009; 122: 305-311. http://dx.doi. org/10.1242/jcs.031146

[59] TOSHIMA J, TOSHIMA JY, TAKEUCHI K, MORI R, MIZUNO K. Cofilin phosphorylation and actin reorganization activities of testicular protein kinase 2 and its predominant expression in testicular Sertoli cells. J Biol Chem 2001; 276: 31449-31458. http://dx.doi.org/10.1074/jbc.M102988200 